\title{
Spectroscopic, Viscositic and Molecular Modeling Studies on the Interaction of 3'-Azido-Daunorubicin Thiosemicarbazone with DNA
}

\author{
Fengling Cui • Qingfeng Liu • Hongxia Luo • \\ Guisheng Zhang
}

Received: 20 May 2013 / Accepted: 9 August 2013 /Published online: 25 August 2013

(C) The Author(s) 2013. This article is published with open access at Springerlink.com

\begin{abstract}
A new daunorubicin has been synthesized and structurally characterized. The interaction of native calf thymus DNA (ctDNA) with 3'-azido-daunorubicin thiosemicarbazone (ADNRT) was investigated under simulated physiological conditions by multi-spectroscopic techniques, viscometric measurements and molecular modeling study. It concluded that ADNRT could intercalate into the base pairs of ctDNA, and the fluorescence quenching by ctDNA was static quenching type. Thermodynamic parameters calculated suggested that the binding of ADNRT to ctDNA was mainly driven by hydrophobic interactions. The relative viscosity of ctDNA increased with the addition of ADNRT, which confirmed the intercalation mode. Furthermore, molecular modeling studies corroborate the above experimental results.
\end{abstract}

Keywords 3'-azido-daunorubicin thiosemicarbazone ·

DNA $\cdot$ Fluorescence $\cdot$ Viscosity $\cdot$ Modeling

\section{Introduction}

As we all know, nucleic acid is the primary intracellular target of antitumor drugs, owing to small molecules interaction with DNA and then damaging the formation of DNA in cancer cells [1]. Thus, the investigation of small molecules binding to DNA is of current general interest and importance in rational design of more powerful and selective anticancer pharmaceuticals and

F. Cui $(\bowtie) \cdot$ Q. Liu $\cdot$ G. Zhang $(\bowtie)$

School of Chemistry and Chemical Engineering, Key Laboratory of

Green Chemical Media and Reactions, Ministry of Education, Henan

Normal University, Xinxiang 453007, China

e-mail: fenglingcui@hotmail.com

e-mail: zgs@htu.cn

H. Luo

Department of Chemistry, Renmin University of China,

Beijing 100872, China their effectiveness depend on the mode and affinity of the binding [2].

Daunorubicin, one of the most widely used anthracyclines, is used for the clinical treatment of a broad range of human malignancies [3]. Like other intercalating agents, daunorubicin is considered to interfere with the function of topoisomerase II, a nuclear enzyme which can regulate the DNA topology [4]. In spite that a great deal of work has been done [5], the mechanism by which these molecules mediate their relatively selective antitumor effects is not yet clear. What's more, severe side effects limited the clinical use of daunorubicin, such as cardiotoxicity, myelosuppression and drug resistance [6]. Many efforts have been made to modify the structure of anthracyclines to generate analogs for the sake of reducing the side effects and reversing multidrug resistance. In our previous works, a lead compound derived from daunorubicin, 3'azido-3'-deamino daunorubicin (ADNR), was synthesized and its bioactivities and the binding to human serum albumin or DNA were also investigated [7-9]. This lead compound exhibited potent anticancer activity in both drug-sensitive (K562) and drug-resistant leukemia cells (K562/Dox), with a 25-fold lower drug resistance index than daunorubicin.

Based on the special bioactivities of ADNR and thiosemicarbazones [10-13], in this paper, we designed and synthesized a hybrid of ADNR with thiosemicabzone, 3'-azidodaunorubicin thiosemicarbazone (ADNRT, inset of Fig. 1), and systematically investigated its interaction with calf thymus DNA (ctDNA) in combination with multi-spectroscopic, viscometric techniques and molecular modeling under simulated physiological conditions ( $\mathrm{pH}$ 7.4). The characteristics in spectroscopy measurements revealed that ADNRT could bind to ctDNA through intercalation binding modes. The results obtained from the viscosity experiments and molecular modeling validated those conclusions. This work provides valuable information on the binding behavior of daunorubicin with DNA and should be helpful for designing the alternative or even more active daunorubicin. 


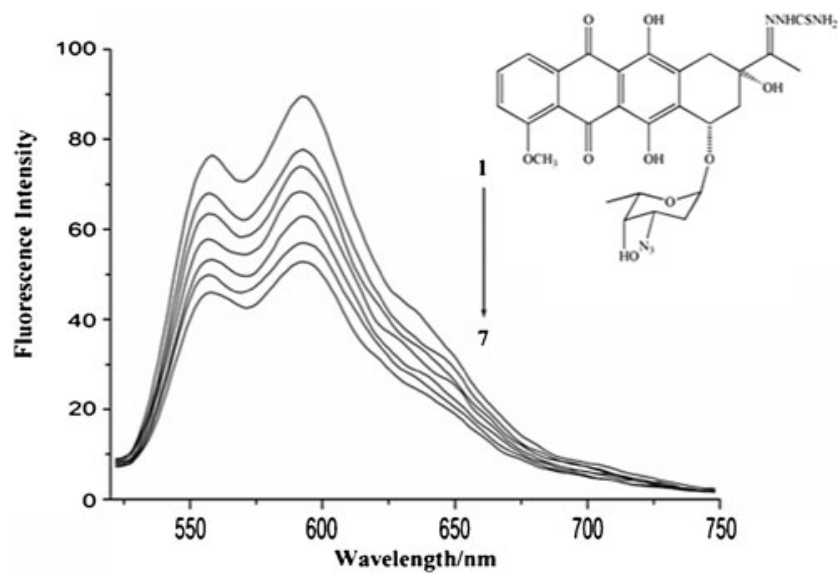

Fig. 1 Fluorescence spectra of ADNRT in the presence of ctDNA (inset: structure of ADNRT). $C_{\mathrm{ctDNA}}=0,4.6,9.2,13.8,18.4,23.0$ and $27.6 \times$ $10^{-6} \mathrm{~mol} \cdot \mathrm{L}^{-1}$ for curves $1-7 ; C_{\mathrm{ADNRT}}=3.3 \times 10^{-6} \mathrm{~mol} \cdot \mathrm{L}^{-1}$

\section{Materials and Methods}

Materials

The preparation procedure for ADNRT: A drop of acetic acid was added to the mixture of ADNR $(27.7 \mathrm{mg}, 0.05 \mathrm{mmol})$ and thiosemicarbazide monohydrochloride (19.1 mg,0.15 mmol) in methanol $(3 \mathrm{~mL})$ and the mixture was stirred overnight. TLC showed the reaction was completed. The solvent was removed, then the residue was diluted with saturated aqueous $\mathrm{Na}_{2} \mathrm{CO}_{3}$ solution and extracted with $\mathrm{CH}_{2} \mathrm{Cl}_{2}(5 \mathrm{~mL})$ for three times. The combined extractions were dried by $\mathrm{Na}_{2} \mathrm{SO}_{4}$ and concentrated. The crude product was purified on a column of silica gel to get the pure product ADNRT as a yellow solid (29.1 mg, $93 \%$ ). HRMS (M + H) ${ }^{+}$(ESI) calcd for $\mathrm{C}_{28} \mathrm{H}_{31} \mathrm{~N}_{6} \mathrm{O}_{9} \mathrm{~S}$ 627.1867, found 627.1860. ${ }^{1} \mathrm{H}$ NMR (400 MHz, DMSO$\left.d_{6}\right): 13.99(1 \mathrm{H}, \mathrm{s}), 13.21(1 \mathrm{H}, \mathrm{s}), 10.08(1 \mathrm{H}, \mathrm{s}), 8.22(1 \mathrm{H}, \mathrm{s})$, 7.87-7.80 (2H, m), 7.57 (1H, d, J=8.0 Hz), 7.24 (1H, s), 5.31 $(1 \mathrm{H}, \mathrm{d}, J=4.0 \mathrm{~Hz}), 5.17(2 \mathrm{H}, \mathrm{m}), 4.84$ (1H, s), 4.10-4.05 $(1 \mathrm{H}, \mathrm{m}), 3.94(1 \mathrm{H}, \mathrm{s}), 3.60(1 \mathrm{H}, \mathrm{d}, J=4.0 \mathrm{~Hz}), 3.49-$ 3.46 (1H, m), $3.13(1 \mathrm{H}, \mathrm{d}, J=16.0 \mathrm{~Hz}), 2.83(1 \mathrm{H}, \mathrm{d}, J=$ $20.0 \mathrm{~Hz}), 2.31(1 \mathrm{H}, \mathrm{dd}, J=4.0 \mathrm{~Hz}, J=12.0 \mathrm{~Hz}), 2.15(1 \mathrm{H}, \mathrm{dd}$, $J=4.0 \mathrm{~Hz}, J=12.0 \mathrm{~Hz}), 2.00(3 \mathrm{H}, \mathrm{s}), 1.69(1 \mathrm{H}, \mathrm{dd}, J=4.0 \mathrm{~Hz}$, $J=12.0 \mathrm{~Hz}), 1.14(3 \mathrm{H}, \mathrm{d}, J=8.0 \mathrm{~Hz}) ;{ }^{13} \mathrm{C} \mathrm{NMR}(100 \mathrm{MHz}$, DMSO- $\left.d_{6}\right): 186.3,186.1,179.1,160.7,156.2,155.5,154.2$, $136.1,135.7,135.5,134.5,119.8,119.5,118.9,110.5,99.6$, 72.2, 70.7, 69.0, 67.0, 56.5, 55.6, 38.1, 33.4, 28.1, 16.9, 11.9.

The stock solution $\left(8.3 \times 10^{-5} \mathrm{~mol} \mathrm{~L}^{-1}\right)$ of ADNRT (synthesized) was prepared. An appropriate amount of solid ctDNA (Sigma-Aldrich Chemicals Company, USA) without further purification was dissolved into the doubly distilled water and stored at $4{ }^{\circ} \mathrm{C}$. The ratio of the absorbance at $260 \mathrm{~nm}$ and $280 \mathrm{~nm}>1.8$, indicated that ctDNA was sufficiently free from protein [14]. The concentration of DNA $\left(4.6 \times 10^{-4} \mathrm{~mol} \mathrm{~L}^{-1}\right)$ in stock solution used for binding experiments was determined by the absorption intensity at $260 \mathrm{~nm}$ using a molar absorption coefficient value of $6600 \mathrm{~L} \mathrm{~mol}^{-1} \mathrm{~cm}^{-1}$ [15]. All regents were of analytical grade, and doubly distilled water was used throughout.

Methods

Absorption Measurements

The UV absorption spectra were recorded on a TU-1810 spectrophotometer (Puxi Analytic Instrument Ltd., Beijing, China) by adding the increments of ctDNA stock solution into a fixed concentration of ADNRT. The solutions were allowed to incubate for $10 \mathrm{~min}$ before the absorption spectra were recorded. The ctDNA solutions of corresponding concentrations were measured as reference solutions. All UV measurements were carried out in Tris- $\mathrm{HCl}$ buffer $(\mathrm{pH}$ 7.4) at room temperature.

\section{Fluorescence Measurements}

All fluorescence measurements were performed on a Varian Cary Eclipse spectrofluorimeter (VARIAN, USA) equipped with a SHP DC-0515 thermostatic bath (Shanghai Hengping Sciences Instrument Co. Ltd., Shanghai, China), and a quartz cuvette of $1 \mathrm{~cm}$ path length. $2.0 \mathrm{~mL} \mathrm{pH} 7.4$ of Tris-HCl buffer solution, certain volume of drug and vary volume of ctDNA solution were transferred to a $10 \mathrm{~mL}$ volumetric flask, and the mixed solution was diluted to the final volume with doubly distilled water. These solutions were allowed to stand for $8 \mathrm{~min}$ to equilibrate. The fluorescence emission spectra were measured at 295,303 and $310 \mathrm{~K}$ in the wavelength range of $520-750 \mathrm{~nm}$ with an excitation wavelength at $254 \mathrm{~nm}$.

\section{Viscosity Measurements}

Viscosity measurements were carried out by Ubbelodhe viscometer, which was immersed in a thermostat water-bath at a constant temperature at $25 \pm 0.1{ }^{\circ} \mathrm{C}$. Various concentrations of ADNRT were then added into the viscometer to give a certain $r(r=[\mathrm{drug}] /[\mathrm{DNA}])$ value while the ctDNA concentration was constant. The flow time of the samples were repeatedly measured by a digital stopwatch with an accuracy of $\pm 0.20 \mathrm{~s}$ after thermal equilibrium was achieved $(15 \mathrm{~min})$. The result of each point was the average of at least three readings. The data were presented as $\eta / \eta_{0}$ versus $r$, where $\eta$ and $\eta_{0}$ are the viscosity of ctDNA in the presence and absence of ADNRT. Viscosity values were calculated from observing the flow time 


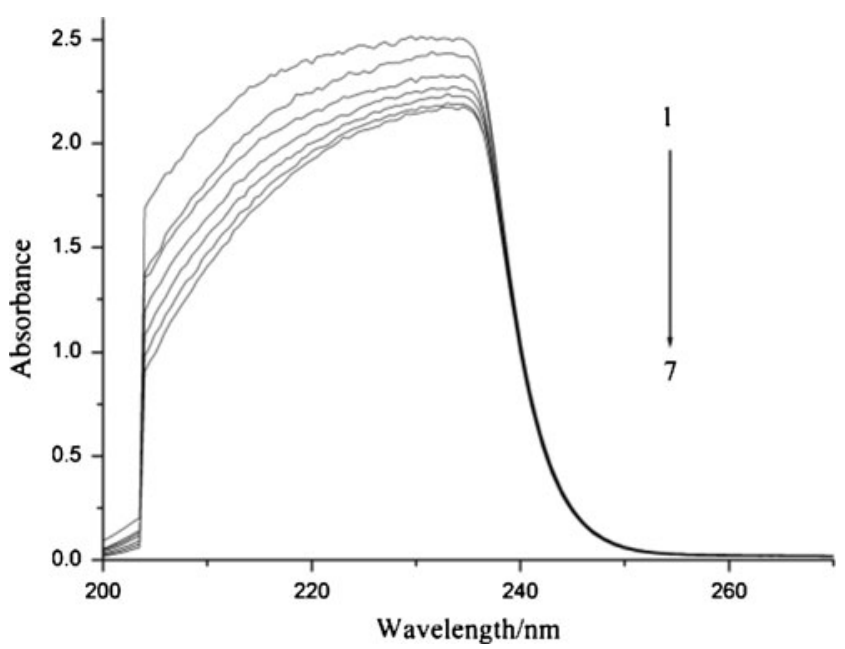

Fig. 2 Absorption spectra of ADNRT in presence of ctDNA at different concentrations (versus corresponding concentration of $\mathrm{ctDNA}$ ) at $\mathrm{pH}=7.4$; Conditions: $C_{\mathrm{ADNRT}}=8.3 \times 10^{-7} \mathrm{~mol} \cdot \mathrm{L}^{-1}$, from 1 to $7: C_{\mathrm{ctDNA}}=0,4.6,9.2$, $13.8,18.4,23.0$ and $27.6 \times 10^{-6} \mathrm{~mol} \cdot \mathrm{L}^{-1}$

of ctDNA containing solutions ( $t>180 \mathrm{~s})$ and corrected by buffer solution $\left(t_{0}\right)$, using $\eta=\left(t-t_{0}\right) / t_{0}[16]$.

\section{Molecular Docking}

The rigid molecular docking study was performed by Sybyl 6.9 software. The crystal structure of the B-DNA was extracted from the structure having Protein Data Bank identifier 425D. The structure of ADNRT was sketched and minimized with the help of the Trops force field using GasteigerMarsili charges. The macromolecule file was prepared for docking by adding polar hydrogen atoms and Gasteiger charges. After DNA was enclosed in the grid defined with $0.375 \AA$ spacing, the grid map was calculated using the FlexX program. Visualization of the docked pose was done by using PyMol.

\section{Results and Discussion}

Interaction Between ADNRT and ctDNA

Spectral Characteristics of ADNRT Binding to ctDNA

It is known that the intrinsic fluorescence of DNA is of little practical use [17], whereas the titled molecule displays luminescent property $\left(\lambda_{\mathrm{ex}} / \lambda_{\mathrm{em}}=254 / 590 \mathrm{~nm}\right)$. Hence, the fluorescence emission spectra of ADNRT in the absence and presence of ctDNA were studied. As shown in Fig. 1, with the increasing amounts of ctDNA, the fluorescence intensity of ADNRT decreased without apparent shift of maximum fluorescence emission wavelength, which indicated the binding of ADNRT to ctDNA indeed existed.

The formation of ADNRT-ctDNA complex was further confirmed by UV absorption spectra (Fig. 2). The UV absorption spectra of ADNRT showed an intense absorption band, assigned to the $\pi-\pi^{*}$ transition of the anthraquinone chromophore [18]. It was apparent that as the concentration of ctDNA increased, the absorption peak at $230 \mathrm{~nm}$ decreased significantly with slight red shift $(2 \mathrm{~nm})$. These spectral changes suggested that ADNRT was likely to interact with ctDNA through some binding modes. Moreover, it is necessary to judge the binding mode of ADNRT with ctDNA by other methods.

\section{The Quenching Mechanism of Fluorescence of ADNRT} by ctDNA

The mechanisms of fluorescence quenching are usually classified as dynamic quenching and static quenching, which can
Fig. 3 a Stern-Volmer curves of ctDNA quenching the fluorescence of ADNRT. b Double logarithmic curves of ctDNA quenching the fluorescence of ADNRT a

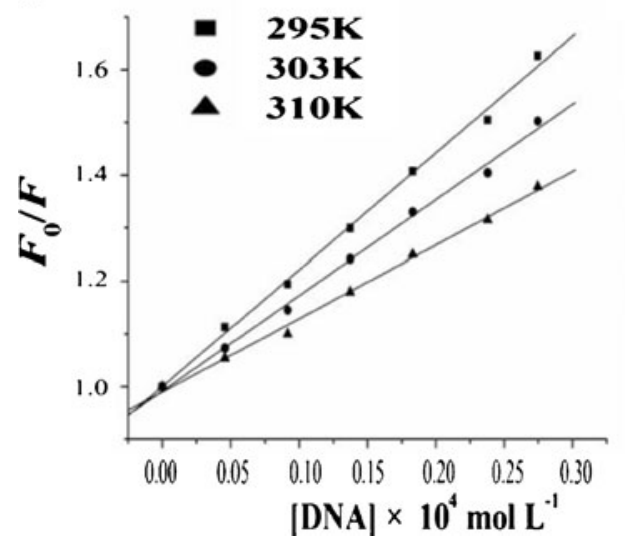

b

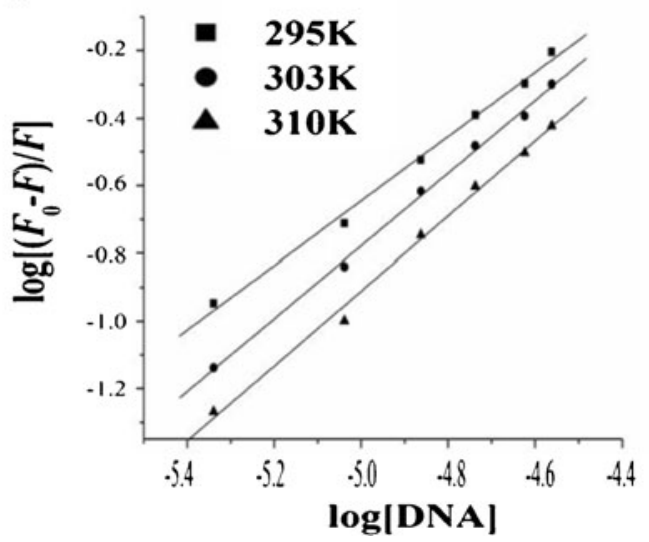


Table 1 Stern-Volmer quenching constants for the interaction of ADNRT with ctDNA at different temperatures

\begin{tabular}{lllll}
\hline$T(\mathrm{~K})$ & Stern-Volmer equation & $K_{\mathrm{SV}}\left(\mathrm{L} \cdot \mathrm{mol}^{-1}\right)$ & $K_{\mathrm{q}}\left(\mathrm{L} \cdot \mathrm{mol}^{-1} \cdot \mathrm{s}^{-1}\right)$ & $R$ \\
\hline 298 & $\mathrm{Y}=1.0002+2.209 \times 10^{4}[\mathrm{DNA}]$ & $2.209 \times 10^{4}$ & $2.209 \times 10^{12}$ & 0.9982 \\
304 & $\mathrm{Y}=0.9915+1.809 \times 10^{4}[\mathrm{DNA}]$ & $1.809 \times 10^{4}$ & $1.809 \times 10^{12}$ & 0.9980 \\
310 & $\mathrm{Y}=0.9899+1.389 \times 10^{4}[\mathrm{DNA}]$ & $1.389 \times 10^{4}$ & $1.389 \times 10^{12}$ & 0.9979 \\
\hline
\end{tabular}

be distinguished by examination of the temperature on the Stern-Volmer equation (Eq. (1)):

$\frac{F_{0}}{F}=1+K_{q} \tau_{0}[D N A]=1+K_{S V}[D N A]$

where $F_{0}$ and $F$ are the fluorescence intensities in the absence and presence of ctDNA, respectively, $K_{\mathrm{q}}$ is the quenching rate constant of biomolecular, $\tau_{0}$ is the average lifetime of the fluorophore and $K_{\mathrm{SV}}$ is the Stern-Volmer quenching constant which can measure the fluorescence quenching efficiency.

It was assumed that the interaction of ADNRT with ctDNA proceeded via a dynamic quenching. The $K_{\mathrm{SV}}$ value was obtained from the slope of the $F_{0} / F$ versus [DNA] linear plot (Fig. 3a), and the values of $K_{\mathrm{SV}}$ and $K_{\mathrm{q}}$ at the three temperatures $(295,303$ and $310 \mathrm{~K})$ are listed in Table 1 . As can be seen, the values of $K_{\mathrm{SV}}$ decreased with the increasing temperature, indicating that the fluorescence quenching of ADNRT by ctDNA was static [19].

\section{Binding Constant and Binding Sites}

For a static quenching interaction, it is often assumed that the binding capability of DNA at each binding site is equal [20]. The binding constant $K$ and the number of binding site n can be calculated by using the double logarithm regression equation,

$\log \frac{F_{0}-F}{F}=\log K+n \log [D N A]$

The values of $K$ and $n$ were obtained from the intercept and slope of the plot of $\log \left[\left(F_{0}-F\right) / F\right]$ versus $\log [\mathrm{DNA}]$ (Fig. 3b). The corresponding results at different temperatures are summarized in Table 2 . The values of $n$ approximately equal to 1 indicated that there was just a single binding site between ctDNA and ADNRT. The increasing trend of $K$ with temperature indicated that the capacity of ADNRT binding to DNA was enhanced with the temperature rising [21].

\section{Thermodynamic Parameters and Nature of Binding Forces}

The acting forces between a small molecule and macromolecule mainly include hydrogen bonds, van der Waals force, electrostatic force and hydrophobic interaction force. To further characterize the interaction forces, the thermodynamic parameters which are the main evidence to determine the binding mode were analyzed. If the enthalpy change $(\Delta H)$ does not vary significantly within the range of temperature, the thermodynamic parameters $\Delta H$ and $\Delta S$ can be estimated using van't Hoff plots [22]:

$\ln K=-\frac{\Delta H}{R T}+\frac{\Delta S}{R}$

The free energy change $(\Delta G)$ was estimated from the Gibbs' equation [23]:

$\Delta G=\Delta H-T \Delta S=-R T \ln K$

The values of $\Delta H$ and $\Delta S$ were obtained from the slope ( $-\Delta H / R, R$ is the gas constant) and intercept $(\Delta S / R)$. The values of $\Delta H, \Delta S$ and $\Delta G$ at different temperature are given in Table 2. The negative values of $\Delta \mathrm{G}$ revealed that the interaction processes was spontaneous, and the positive $\Delta H$ and $\Delta \mathrm{S}$ values associated indicated that the hydrophobic interaction played a major role [24].

\section{Effect of Ionic Strength on the Spectrum of ADNRT-ctDNA}

In order to prove the binding mode of ADNRT with ctDNA, the effect of different concentrations of $\mathrm{NaCl}$ (from 0 to $0.25 \mathrm{~mol} \mathrm{~L}^{-1}$ ) on the fluorescence of ADNRT-ctDNA system
Table 2 The binding constants, number of binding sites and thermodynamic parameters of the interaction of ADNRT with ctDNA at different temperatures

\begin{tabular}{lllllll}
\hline$T(\mathrm{~K})$ & $K\left(\mathrm{~L} \cdot \mathrm{mol}^{-1}\right)$ & $n$ & $R$ & $\Delta G\left(\mathrm{~kJ} \cdot \mathrm{mol}^{-1}\right)$ & $\Delta H\left(\mathrm{~kJ} \cdot \mathrm{mol}^{-1}\right)$ & $\Delta S\left(\mathrm{~J} \cdot \mathrm{mol}^{-1} \cdot \mathrm{K}^{-1}\right)$ \\
\hline 295 & $1.319 \times 10^{4}$ & 0.953 & 0.9972 & -23.616 & & \\
303 & $3.980 \times 10^{4}$ & 1.076 & 0.9987 & -25.911 & 61.020 & 286.900 \\
310 & $4.273 \times 10^{4}$ & 1.108 & 0.9972 & -27.919 & &
\end{tabular}




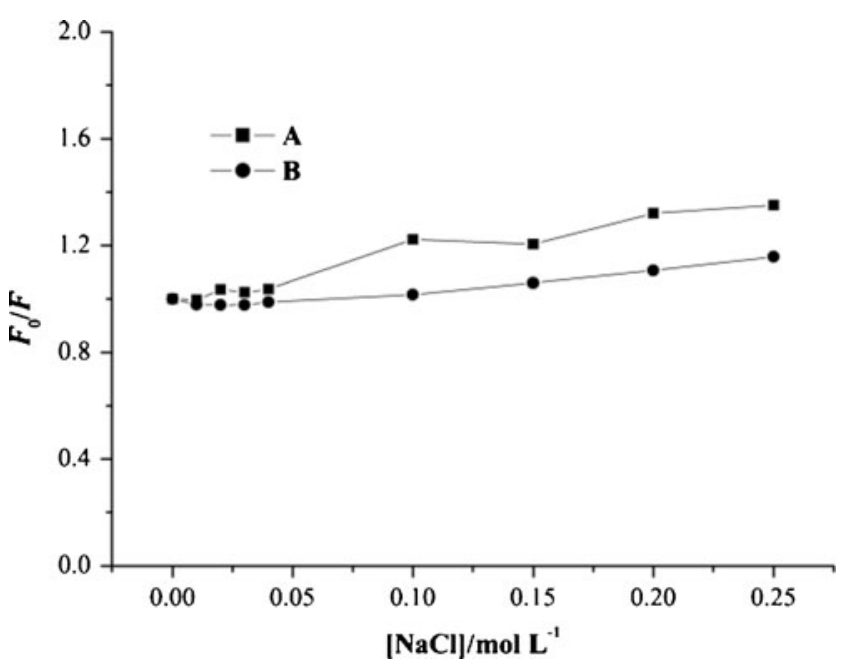

Fig. 4 Effect of ionic strength on the fluorescence intensity of ADNRT and ADNRT-ctDNA system. $C_{\mathrm{ADNRT}}=0.1 \times 10^{-6} \mathrm{~mol} \cdot \mathrm{L}^{-1} ; C_{\mathrm{ctDNA}}=$ $9.1 \times 10^{-6} \mathrm{~mol} \cdot \mathrm{L}^{-1} ; C_{\mathrm{NaCl}}=0.01,0.02,0.03,0.04,0.05,0.10,0.15$, $0.20,0.25 \mathrm{~mol} \cdot \mathrm{L}^{-1}$

and free compound was investigated. It represented that the fluorescence intensity was not dependent on ionic strength. When $\mathrm{NaCl}$ exists in the system, the electrostatic repulsion between the negatively charged phosphate skeletons on adjacent nucleotides is reduced with the increasing concentration of $\mathrm{Na}^{+}$[25]. Apparently, the groove bound molecules can be released from the helix by increasing the ionic strength, whereas it is difficult for the intercalation bound molecules to be released, owing that a small molecule binding in the groove of DNA duplex exposes much more to the solvent surrounding than it does for the intercalation [26]. As seen from Fig. 4, the results demonstrated that the effect of ionic strength on the ADNRT-ctDNA system was very limited, so the interaction between ADNRT and ctDNA was intercalative binding.
Iodide Quenching Studies

Fluorescence quenching is a reliable method to study the binding of small molecules to DNA. A highly negatively charged quencher such as $\mathrm{I}^{-}$ion is expected to be repelled by the negatively charged phosphate backbone of DNA $[27,28]$. Therefore, the molecules buried by intercalating into the helix will be protected from being quenched by $\mathrm{I}^{-}$, while the free aqueous complex and groove binding molecule should be quenched readily [9]. Figure 5a depicts the Stern-Volmer plots of the free ADNRT and the ADNRT-ctDNA system in the presence of KI. The values of $K_{\mathrm{Sv}}$ for free ADNRT and the ADNRT-ctDNA system were $419.23 \mathrm{~L} \mathrm{~mol}^{-1}$ and $303.85 \mathrm{~L} \mathrm{~mol}^{-1}$, respectively. It was obvious that the quenching effect for free ADNRT was stronger than that of the bound ADNRT, suggesting that an intercalation binding should be the interaction mode of ADNRT with ctDNA [29].

Comparison of the Interaction of ADNRT with dsDNA and ssDNA

The behaviors of native DNA and denatured DNA were compared. Double-strand DNA was converted into singlestrand DNA with the opening of its double helix by incubation at $100{ }^{\circ} \mathrm{C}$ for $30 \mathrm{~min}$ followed by rapid cooling in ice water [30]. Generally, thermal denaturation involves the rupture of hydrogen bonds and no covalent bonds are expected to be broken. If the interaction between ADNRT and DNA belonged to a groove binding mode, the extent of the fluorescence quenching of ADNRT would be stronger by ssDNA than that by dsDNA [31]. The results of the comparison experiments are given in Fig. 5b. The fluorescence quenching of ADNRT by ssDNA was smaller than that by dsDNA, which also supported that ADNRT intercalated into the helix stack.
Fig. 5 a Fluorescence quenching plots of ADNRT by KI in the absence and presence of ctDNA. $C_{\text {ctDNA }}=9.2 \times 10^{-6} \mathrm{~mol} \cdot \mathrm{L}^{-1}$, $C_{\mathrm{ADNRT}}=3.3 \times 10^{-6} \mathrm{~mol} \cdot \mathrm{L}^{-1} ; \mathbf{b}$ Effect of dsDNA and ssDNA on the ADNRT fluorescence intensity, $C_{\mathrm{ADNRT}}=3.3 \times 10^{-6} \mathrm{~mol}$ $\cdot \mathrm{L}^{-1}$ a

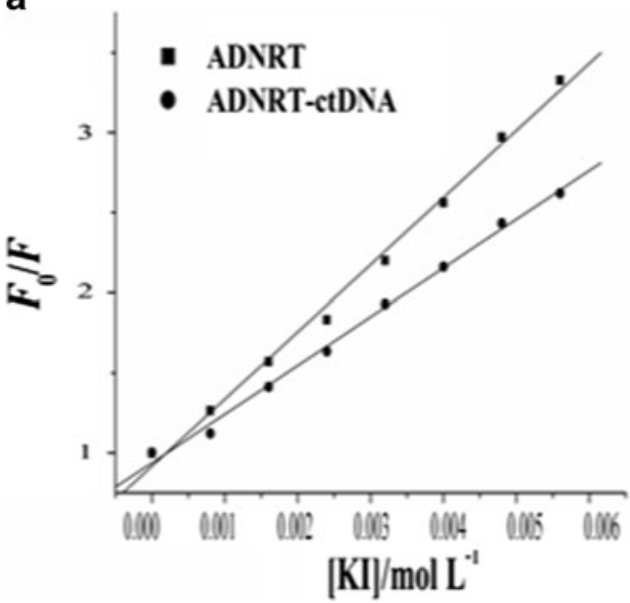

b

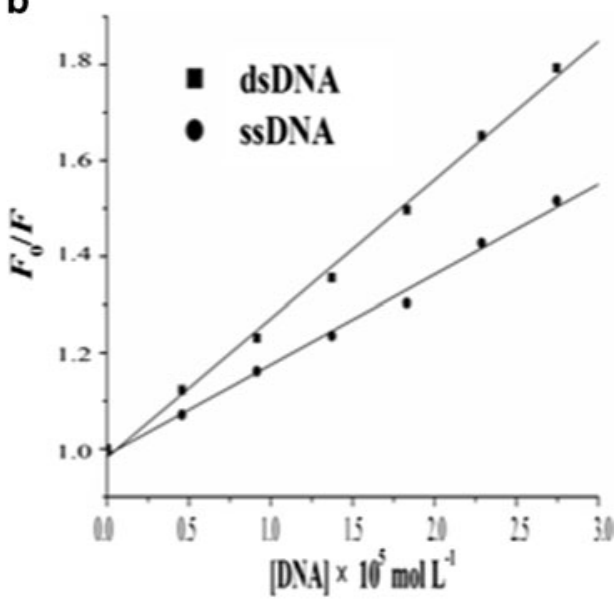




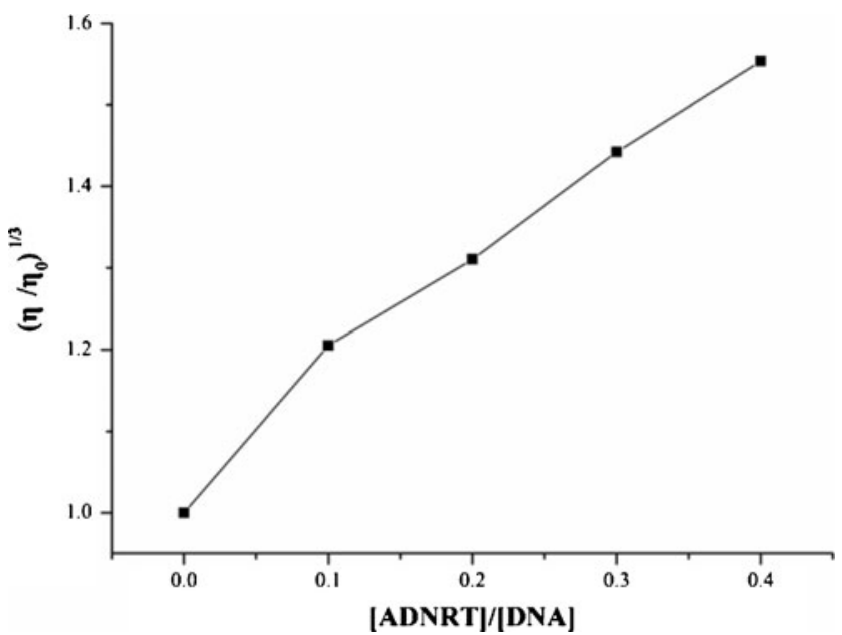

Fig. 6 Effect of increasing amount of ADNRT on the relatively viscosity of ctDNA

\section{Viscosity Measurements}

Optical photophysical studies provide necessary but not sufficient clues to explain a binding between DNA and the complex, while hydrodynamic measurements that are sensitive to the length change are regarded as the least ambiguous tests of a binding model in solution [32]. Thus, viscosity measurements were carried out as an effective tool to further clarify the binding mode of ADNRT to ctDNA. An intercalator is generally known to cause a significant increase in the viscosity of a DNA solution due to lengthen the DNA helix as base pairs are separated to accommodate the binding ligand [33]. In contrast, a partial, non-classical ligand intercalation in grooves causes a bend in DNA helix reducing its effective length and thereby its viscosity [34]. As illustrated in Fig. 6, the relative viscosities of

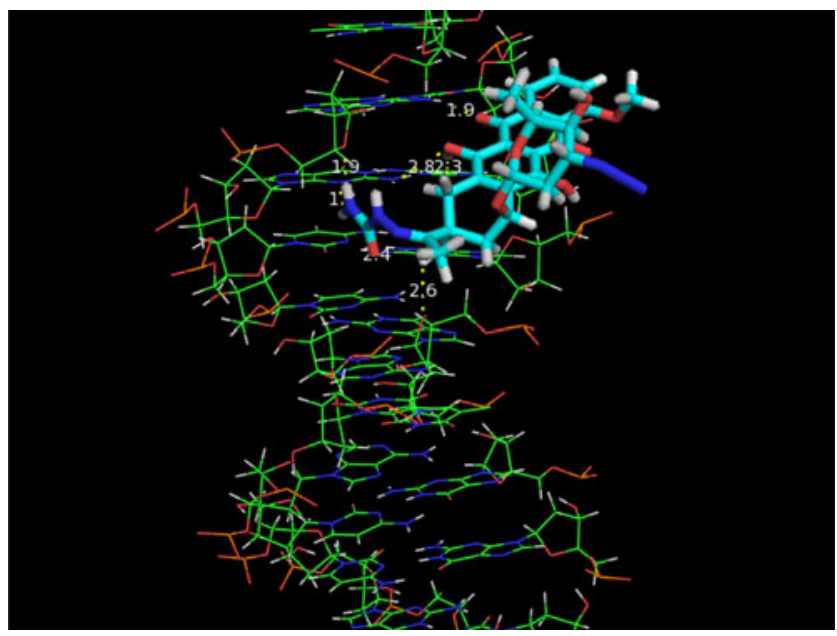

Fig. 7 Computational docking model of the binding of ADNRT to ctDNA the ctDNA increased steadily upon the increasing concentrations of ADNRT. Such behavior further confirmed that ADNRT bound to DNA through an intercalative binding mode.

\section{Molecular Docking}

Molecular docking technique is an attractive scaffold to understand the drug-DNA interactions which can help to design and discover the rational drug. As shown in Fig. 7, ADNRT was successively docked with DNA duplex of sequence dodecamer (PDB ID: 425D) to search the optimal energy ranked results along with preferred orientation of the ligand inside the DNA groove. It revealed that the chromophore of ADNRT seemed to be mainly intercalated between guanine and cytosine base pairs of DNA. In addition, hydrogen bondings were prone to form between the amino group $\mathrm{H}$ of $\mathrm{G}$ or, the carbonyl $\mathrm{O}$ of $\mathrm{C}$, and the intercalator. In this case, the hydroxy O of ADNRT was at a distance of $2.8 \AA$ from azyl $\mathrm{H}$ atom of $\mathrm{G} 10$, the hydroxy $\mathrm{H}$ atom was $2.3 \AA$ from the $\mathrm{O} 2$ of $\mathrm{C} 15$, the carbonyl $\mathrm{O}$ atom was $1.9 \AA$ from the $\mathrm{N}-2 \mathrm{H}$ atom of G10. The results of molecular modeling indicated that the interaction between ADNRT and ctDNA was intercalation dominated and hydrogen bonding forces might play an essential role in the binding. This result was consistent with the above spectroscopic and viscosity experiments.

\section{Conclusion}

The interaction between ADNRT and ctDNA was studied by spectral analysis, viscosity method and molecular docking. Hypochromic effects in UV and fluorescence spectroscopy showed that ADNRT could interact with ctDNA through static quenching mechanism. The binding constants and the number of binding sites of ADNRT binding to ctDNA were measured at different temperatures and the thermodynamic parameters were calculated as well. It was found that hydrophobic force played a significant role in the binding. The intercalative binding was much more reasonable by taking account of ionic strength effects, tests for the ability of ADNRT binding with dsDNA and ssDNA, KI quenching studies, and the viscosity measurements. The results obtained from molecular docking corroborated the experimental results obtained from spectroscopic investigations. This combination of spectroscopic and molecular modeling methods were expected to provide important insight into designing new antiviral anthracyclines.

Acknowledgments We gratefully acknowledge the financial support of National Natural Science Foundation of China (30970696, 21172056, 21075136)) and PCSIRT (IRT1061), and the Program for Innovative Research Team from the University of Henan Province (2012IRTSTHN006). 
Open Access This article is distributed under the terms of the Creative Commons Attribution License which permits any use, distribution, and reproduction in any medium, provided the original author(s) and the source are credited.

\section{References}

1. Kashanian S, Khodaei MM, Roshanfekr H, Shahabadi N, Mansouri G (2012) DNA binding, DNA cleavage and cytotoxicity studies of a new water soluble copper(II) complex: the effect of ligand shape on the mode of binding. Spectrochim Acta, Part A 86:351-359

2. Mazzini S, Scaglioni L, Animati F, Mondelli R (2010) Interaction between double helix DNA fragments and the new antitumor agent sabarubicin, Men10755. Bioorg Med Chem 18:1497-1506

3. Xu DL, Wang XM, Ding LS (2011) Spectroscopic studies on the interaction of $\gamma$-cyclodextrin-daunorubicin inclusion complex with herring sperm DNA. Carbohydr Polym 83:1257-1262

4. Htun MT (2009) Photophysical study on daunorubicin by fluorescence spectroscopy. J Lumin 129:344-348

5. Wang J, Ozsoz MX, Cai H, Rivas G, Shiraishi H, Grant DH, Chicharro M, Fernandes J, Paleček E (1998) Interactions of antitumor drug daunomycin with DNA in solution and at the surface. Bioelectrochem Bioenerg 45:33-40

6. Stepankova J, Studenovsky M, Malina J, Kasparkova J, Liskova B, Novakova O, Ulbrich K, Brabec V (2011) DNA interactions of 2-pyrrolinodoxorubicin, a distinctively more potent daunosamine-modified analogue of doxorubicin. Biochem Pharmacol 82:227-235

7. Fang L, Zhang G, Li C, Zheng X, Zhu L, Xiao JJ, Szakacs G, Nadas J, Chan KK, Wang PG, Sun D (2006) Discovery of a daunorubicin analogue that exhibits potent antitumor activity and overcomes P-gpmediated drug resistance. J Med Chem 49:932-941

8. Lu Y, Feng QQ, Cui FL, Xing WW, Zhang GS, Yao XJ (2010) Interaction of 3'-azido-3'-deamino daunorubicin with human serum albumin: Investigation by fluorescence spectroscopy and molecular modeling methods. Bioorg Med Chem Lett 20:6899-6904

9. Cui FL, Hui GQ, Jiang XY, Zhang GS (2012) Interaction of 3'-azido3'-deamino daunorubicin with DNA: Multispectroscopic and molecular modeling. Int J Biol Macromol 50:1121-1126

10. Brockman RW, Thomson JR, Bell MJ, Skipper HE (1956) Observations on the antileukemic activity of pyridine-2carboxaldehyde thiosemicarbazone and thiocarbohydrazone. Cancer Res 16:167-170

11. Jutten P, Schumann W, Hartl A, Dahse HM, Grafe U (2007) Thiosemicarbazones of formyl benzoic acids as novel potent inhibitors of estrone sulfatase. J Med Chem 50:3661-3666

12. Easmon J, Purstinger G, Heinisch G, Roth T, Fiebig HH, Holzer W, Jager W, Jenny M (2001) Synthesis, cytotoxicity, and antitumor activity of copper(II) and iron(II) complexes of (4)Nazabicyclo[3.2.2] nonane thiosemicarbazones derived from acyl diazines. J Med Chem 44:2164-2171

13. Huang H, Chen Q, Ku X, Meng LH, Lin LP, Wang X, Zhu CH, Wang Y, Chen Z, Li M, Jiang HL, Chen KX, Ding J, Liu H (2010) A series of $\alpha$-heterocyclic carboxaldehyde thiosemicarbazones inhibit topoisomerase II $\alpha$ catalytic activity. J Med Chem 53:3048-3064

14. Li HY, Yang TL, Ding L, Wang WH (2012) Synthesis, characterization, fluorescence and DNA-binding studies of europium(III) pirates complexes with amide-based 2,3-dihydroxynaphthalene derivatives. J. Rare Earths 30:297-303
15. Jin LH, Tan LF, Zou XQ, Liu J, Luan F (2012) DNA-binding and cytotoxicity studies of ruthenium(II) mixed-ligand complexes containing two intercalative ligands. Inorg Chim Acta 387:253-260

16. Cui FL, Huo RN, Hui GQ, Lv XX, Jin JH, Zhang GS, Xing WW (2011) Study on the interaction between aglycon of daunorubicin and calf thymus DNA by spectroscopy. J Mol Struct 1001:104-110

17. Bi SY, Zhang HQ, Qiao CY, Sun Y, Liu CM (2008) Studies of interaction of emodin and DNA in the presence of ethidium bromide by spectroscopic method. Spectrochim Acta, Part A 69:123-129

18. Zhang GW, Guo JB, Pan JH, Chen XX, Wang JJ (2009) Spectroscopic studies on the interaction of morin-Eu(III) complex with calf thymus DNA. J Mol Struct 923:114-119

19. Zhang GW, Fu P, Wang L, Hu MM (2011) Molecular spectroscopic studies of Farrerol interaction with calf thymus DNA. J Agric Food Chem 59:8944-8952

20. Sun YT, Bi SY, Song DQ, Qiao CY, Mu D, Zhang HQ (2008) Study on the interaction mechanism between DNA and the main active components in Scutellaria baicalensis Georgi. Sens Actuators, B 129:799-810

21. Zhang GW, Guo JB, Zhao N, Wang J (2010) Study of interaction between kaempferol-Eu ${ }^{3+}$ complex and DNA with the use of the neutral red dye as a fluorescence probe. Sens Actuators, B 144:239-246

22. Xu M, Ma ZR, Huang L, Chen FJ, Zeng ZZ (2011) Spectroscopic studies on the interaction between Pr(III) complex of an ofloxacin derivative and bovine serum albumin or DNA. Spectrochim Acta, Part A 78:503-511

23. Lu Y, Xu MH, Wang GK, Zheng Y (2011) Interaction of diethyl aniline methylphosphonate with DNA: Spectroscopic and isothermal titration calorimetry. J Lumin 131:926-930

24. Huang JH, Wang XM (2012) Spectroscopic investigations of interactions between Hematoxylin- $\mathrm{Ag}^{+}$complex and Herring-sperm DNA with the aid of the acridine orange probe. J Mol Struct 1010:73-78

25. Yang X, Liu WH, Jin WJ, Shen GL, Yu RQ (1999) DNA binding studies of a solvatochromic fluorescence probe 3-methoxybenzanthrone. Spectrochim Acta, Part A 55:2719-2727

26. Sun YT, Zhang HQ, Bi SY, Zhou XF, Wang L, Yan YS (2011) Studies on the arctiin and its interaction with DNA by spectral methods. J Lumin 131:2299-2306

27. Zhang GW, Hu X, Fu P (2012) Spectroscopic studies on the interaction between carbaryl and calf thymus DNA with the use of ethidium bromide as a fluorescence probe. J Photochem Photobiol, B 108:53-61

28. Gholivand MB, Kashanian S, Peyman H (2012) DNA-binding, DNA cleavage and cytotoxicity studies of two anthraquinone derivatives. Spectrochim Acta, Part A 87:232-240

29. Khorasani-Motlagh M, Noroozifar M, Khmmarnia S (2011) Study on fluorescence and DNA-binding of praseodymium(III) complex containing 2,2'-bipyridine. Spectrochim Acta, Part A 78:389-395

30. Song GW, Cai ZX, He Y, Lou ZW (2004) The fluorescence studies of interaction between 4-( $n$-2'-glucosyl) butyramidyl triphenyl phosphonium chloride and DNA. Sens Actuators, B 102:320-324

31. Ni YN, Wei M, Kokot S (2011) Electrochemical and spectroscopic study on the interaction between isoprenaline and DNA using multivariate curve resolution-alternating least squares. Int J Biol Macromol 49:622-628

32. Strekowski L, Wilson B (2007) Noncovalent interactions with DNA: an overview. Mutation Research 623:3-13

33. Li YP, Yang P (2010) Synthesis, Crystal Structure, and DNA-binding properties of a new $\mathrm{Cd}(\mathrm{II})$ complex involving 2-(2-1H-Imidazolyl)$1 H$-Imdazolium ligand. Chin J Chem 28:759-765

34. Zhao N, Wang XM, Pan HZ, Hu YM, Ding LS (2010) Spectroscopic studies on the interaction between tryptophan-erbium(III) complex and herring sperm DNA. Spectrochim Acta, Part A 75:1435-1442 